\title{
Ways to Improve the Financial Quality of Enterprises
}

\author{
Yi Yang \\ Business School \\ Sichuan University \\ Chengdu, China
}

\author{
Shengdao Gan \\ Business School \\ Sichuan University \\ Chengdu, China
}

\begin{abstract}
Economic development in China has shifted from a high-speed growth stage to a high-quality growth stage. The government departments such as the Ministry of Finance and the China Securities Regulatory Commission have continuously introduced relevant policies to improve the quality of listed companies from the top-level design. The key to improve the quality of listed companies is to improve the financial quality of enterprises. Most of the existing research on financial quality focuses on the analysis (method) and evaluation of financial quality of enterprises, and particular attention are paid to the quality of individual assets and the quality of earnings. With the continuous development of information technology, financial quality should contain a more comprehensive connotation in today's era of pursuing fairness and efficiency. Although there is no lack of research on corporate financial relations and its essential impact on corporate performance, this paper innovatively proposes to incorporate financial relationship quality as an important component into financial quality research. This paper attempts to provide some ideas for enterprises to explore ways to improve financial quality from the aspects of financial information quality, financial activity quality and financial relationship quality, which could provide reference value for enterprise practice and enrich financial quality research.
\end{abstract}

Keywords-financial quality; financial information quality; financial activity quality; financial relationship quality; improvement approach

\section{INTRODUCTION}

The concept of "quality" has penetrated into all aspects, becoming increasingly popular significant. The World Bank's latest China Economic Outlook redefined the Chinese economic keywords as "high quality". After the outbreak of the international financial crisis, the world's economy structure has been constantly changing. With the intrinsic support conditions of China's economic development and the profound changes in the external demand environment, China's economy has shifted from a high-speed growth stage to a high-quality growth stage. The 19th National Congress, the National Financial Work Conference and the Central Economic Work Conference clearly stated that more attention should be paid to the important conclusions of the quality of listed companies. The CSRC continued to introduce new measures to improve the quality of listed companies after the "New National Nine Articles". The improvement of the quality of listed companies depends on the implementation of corporate financial quality's improvement.
Under the conditions of commodity economy, the goal of the enterprise is to maintain and increase the value of capital, which is also the financial goal of enterprises. Professor Qian Aimin's research found that the quality of listed companies reflects the company's comprehensive results through management and governance activities, including corporate governance characteristics, institutional norms, management activities, economic consequences, and governance effects, can be finally reflected in the financial quality.

Therefore, the key to all types of enterprises, as a carrier of economic development, especially the listed company as the backbone of the national economy and the cornerstone of the capital market, moving from extensive growth to qualityefficient intensive growth is to improve the financial quality.

\section{DEFINITION OF QUALITY AND FINANCIAL QUALITY}

In ISO 8402-94, Quality Management and Quality Assurance - Terminology, quality is defined as the sum of the characteristics that reflect the ability of an entity to meet explicit and implicit needs. From this definition, it can be seen that the quality is measured by whether the quality characteristics meet people's needs and the extent to which the needs are met. That is similar to the definition of quality by the International Organization for Standardization, which is defined as: "The extent to which a set of inherent characteristics meets the requirements."

For the definition of financial quality concept, Professor Zhang Xinmin's research views that financial quality can be understood as the financial status of the enterprise, that is, all aspects that the enterprise can express in currency. Zhang Pengfei defines the concept of "financial quality" as: the combination of corporate financial resources and the financial effects they produce to meet regulatory or potential needs. Li Xiaojing believes that corporate financial quality is the level of efficiency and outcome of corporate financial activities. The research analyzes the financial quality of the enterprise from three aspects: management quality, investment quality and financing quality, and summarizes the corresponding relationship between financial quality and management activities from the above three aspects.

Based on the above discussion, combined with the purpose of this paper, this paper defines financial quality as: the efficiency of value creation and the pros and cons of the results of the various resources owned (controlled) by the enterprise. 


\section{WAYS TO IMPROVE THE FINANCIAL QUALITY OF ENTERPRISES}

Corporate finance consists of both financial activities and financial relationships. Corporate financial information, as a common business language, is a monetized representation of financial activities and financial relationships. It reflects and supervises the creation process of wealth on the one hand, and on the other, it aims to alleviate the information asymmetry between the inside and outside of the enterprise and among parties within the enterprise, and coordinate the interests of the parties to the contract. Therefore, the financial quality of the enterprise should consist of the three levels of financial information quality, financial activity quality and financial relationship quality.

With the development of an open economy, information elements are indispensable in the market economy and play an increasingly critical role in the growth of enterprises. With the development of network and communication technologies and the extensive application of computers to enterprises, network information technologies such as Internet, cloud computing and artificial intelligence have created conditions for enterprises to integrate business, accounting and finance. Enterprise financial information can realize time and space unification, to provide more effective support for corporate managers' financial decisions.

In the same fairness and efficiency has become a core issue of concern corporate finance today, it's incomplete for academic research and business practice to focus just on the quality of financial activity. Most scholars agree that finance is composed of financial activities and financial relationships. Financial activities composed of business activities, fundraising activities, investment activities should be efficient, that is, create more wealth for shareholders; financial relationships, including the relationship between internal and external stakeholders, should pay attention to fairness pursuit of harmony, taking the legal interest of stakeholders besides the shareholders into account. The issue of fairness in financial relations has not been settled, which in turn would affect the efficiency of financial activities, and ultimately impact on the financial quality of enterprises. Ignoring the quality of financial relationships when people talk about the financial quality of financial activities is obviously inappropriate.

\section{IMPROVING THE QUALITY OF FINANCIAL INFORMATION (THE BASIC WAY)}

Relying on the construction of financial information technology to improve the quality of financial information of enterprises is the basic way. Financial information is a concentrated reflection of the company's production and operation activities, and is the basis for supporting production and management decisions. The quality of corporate financial information is the efficiency of the value creation of the information resources used by enterprises and the pros and cons of the results. There are numerous users of financial information, which can be summarized as external use subjects and internal use subjects. The appeal of external entities is mainly based on the financial reports and other relevant information provided by enterprises to analyze the financial quality of their business, so as to realize the rationality and scientificity of investment decisions. The internal entities conducting more comprehensive, in-depth and meticulous research on this basis, they analyze the reasons for the current financial situation and financial results of the enterprise, and perspective the business activities of the enterprise in order to make timely or adjust financial decisions, thereby promoting the healthy growth of the enterprise and maximizing the value of the enterprise. In summary, the quality requirements of financial information mainly include reliability, relevance, comprehensibility, importance and timeliness.

The information revolution strengthens the role of financial accounting information in reflecting economic information, bringing not only massive financial data and doubling efficiency, but also real-time transmission and sharing of financial information, thus helping enterprises to improve the accuracy of financial decisions. In the context of today's information technology, enterprises can improve the financial information quality of enterprises through financial information construction and internal controlling improvement.

\section{A. Financial Information Construction}

Enterprise financial informationization refers to the enterprise's financial system as the core content, relying on modern information technology means to form an information system for rapid collection and processing of financial information, realize the integration of business and finance, and improve the timeliness and accuracy of accounting operations. That assists corporate decision makers grasp business dynamics and achieve results in real time, with information disclosure being more timely and transparent. According to the latest research by Associate Professor $\mathrm{Lu}$ Xingfeng, the financial informationization based on financial integration can be inspired by the following three aspects:

\section{1) Strategic planning:}

First of all, about the target, the core of informatization construction of industry and finance integration is to require business and finance to start from the top-level strategic goals, rather than separate management, finance to the front of the business to help design business analysis indicators, assist enterprise information communication, monitor business activities, and conduct decision analysis.

Second, about the mechanism, establishing a horizontal and vertical financing mechanism, each business work must reflect the role of finance, and the starting point and end point of each business should be implemented into finance.

Finally, about the process, the end of most information flow is the financial department. It is necessary to ensure that every part of the business has the participation of the financial department, and the financial departments will feedback the information to the business in a timely manner. This starts from the basic and critical aspects of the process. 


\section{2) Financial decision support:}

First of all, it's the content. Finance should be infiltrated into various departments and links of business operations (such as procurement management, production management, performance appraisal, logistics management, customer management, product management, marketing, after-sales management, etc.) to distinguish between pre-, post-, and post-event situations. According to the needs of the business, reasonable resource allocation is carried out, and the efficiency of the input resources is evaluated to ensure effective connection with the business and real-time sharing of financial information.

Then, it's the method. Enterprises should utilize financial corresponding information technology methods to analyze related products, costs, technologies, profits, etc., and update with the management characteristics and business changes.

\section{3) Basic sharing:}

First of all, in terms of organization, it is important to explore a support team suitable for the enterprise's financial integration informationization construction. The business department has a finance commissioner. At the same time the financial staff sinks to the business department, to cultivate specialized financial personnel. To build a two-way education mechanism, enterprises should assess financial knowledge for business personnel and business knowledge for financial personnel.

Second, about the data, the foundation of the enterprise financial information system is the effective integration of business and financial data, taking into account financial and non-financial data, internal and external data, quantitative and non-quantitative data. To consider the integration of all links of data, data collection, input, maintenance, processing, storage, output, sharing, transmission, and application should all be carried out according to certain processes and standards.

\section{B. Internal Controlling Improvement}

It is necessary to improve the internal control of enterprises by using information system. An effective financial information system can improve the management efficiency of enterprises, but information technology is only a tool and a means, and cannot replace good internal control. Internal control affects the formation process of corporate financial reporting through the five interrelated elements of internal environment, risk assessment, control activities, information and communication, and supervision, thus affecting the quality of financial information. The enterprise financial information system is a brand-new work platform, which can record and save all the work processes of the staff in detail, greatly improve the monitoring of personnel management, and ensure that the financial personnel carry out relevant financial work in an orderly, efficient and transparent manner.

\section{IMPROVING THE QUALITY OF FINANCIAL ACTIVITIES (THE FUNDAMENTAL WAY)}

Corporate financial activities consist of business activities, investment activities and financing activities. The quality of financial activities is the core content of corporate financial quality. This paper explores ways to improve the quality of financial activities from three aspects: management quality, investment quality and financing quality. Also it is necessary to make clear that financial activities and financial relationships are mutually integrated and mutually influential, and there are no clear-cut boundaries between them, as can be seen in the discussion below.

\section{A. Improving Management Quality}

The quality of operation is an intrinsic disclosure of the company's operating level. It refers to the level of efficiency of the business activities and the extent of the results. The characteristics include profitability, liquidity, safety, and the effectiveness and sustainability of the operating assets. The author believes that the "liquidity" mainly depends on the financial relationship management between the enterprise and the outside.

The core competitiveness of enterprises is the lifeline of sustainable and healthy development of the market economy. Professors of the University of Michigan's School of Business, Prahalad and Hamel, have proposed a considerably famous "Tree Theory" to describe the importance of the core competitiveness of enterprises. The theory compares the core competence to the root of the enterprise's competitive advantage; the core product grows from the root of the capability, and then various final products produces from the core product to each business unit. Applying the theory to the improvement of enterprise management quality, the core competitiveness of the enterprise means that the enterprise must have its own leading product or leading business, and upgrading the core competitiveness is the key to improving the quality of operation. In the research, Xiaojing Li puts that the income generated by the leading products or leading businesses accounts for the total income and the cost of the total expenses, which determines the current survival and future development of the enterprise. Especially in a country with rapid economic development like China, the desire for capital expansion being strong, enterprises are likely to be blindly diversified and diversified. They are blindly pursuing "bigger" and neglecting "strengthening", leading to unclear main business and poor profitability of the main business. There is no sustained and stable profit base, which will inevitably affect the quality of operations.

\section{B. The Increase in Investment Quality}

The investment here refers to the internal investment such as the acquisition, construction and disposal of longterm assets of the enterprise, excluding foreign investment within the scope of cash equivalents and its disposal. Investment quality characteristics include the consistency of investment and corporate development strategies, the effectiveness of investment assets, risk, profitability, and liquidity. 
The level of corporate investment management determines the quality of corporate investment. The author believes that the construction of a composite high-quality financial talent team is the most effective way to improve investment quality. Professor Gan puts forward that in the "changing" and "unchanging" of future accounting, for ability the combination of financial talents needs to have the ability to expand from learning ability to innovation ability, integration ability and management ability; for thinking, they should integrate global thinking, logical thinking, and program-based thinking; for skills, they need to integrate accounting knowledge, IT knowledge, management knowledge, economic knowledge, and social knowledge. Such high-quality talents not only provide professional and reliable guarantee for the decision-making of enterprise investment decision-making and operation decision-making, but also guarantee the continuous and healthy development of enterprises to obtain core competitive advantages.

In addition, in recent years, with the rapid development of China's financial industry integrated operations, more and more non-financial companies invest in financial institutions, and some entities operate a certain range of financial services, participating in financial holding companies to varying degrees. Non-financial corporate investment financial institutions are double-edged swords, which can bring multiple benefits to enterprises, such as meeting financial service demand, improving capital profitability, reducing transaction costs and creating synergistic value, which can improve the financial quality of enterprises. It also contains a range of potential risks. While complying with the new national regulations to encourage financial innovation to serve the real economy and actively invest in financial business, enterprises should rationalize the relationship between finance and entities, return to the main business and focus on the main business.

\section{Raising the Financing Quality}

The quality of financing refers to the degree to which the capital structure formed by the company raising funds is compatible with its current and future business and development activities. The quality characteristics include the relationship between capital cost and return on assets, the appropriateness of asset allocation and financial leverage, control retention, and financial flexibility.

When considering the quality of corporate financing, companies should focus on the appropriateness of asset allocation, that is, whether the cooperation between funding sources and capital use is appropriate. There are three main types of matching forms: adventurous structure, stable structure and matching structure. First, the risk-based structure means that corporate funds are mainly derived from debt financing, especially current liability financing. Current liabilities must not only meet the needs of all temporary liquid assets, but also meet the needs of stable liquid assets and long-term assets. Second, a stable structure means that corporate funds are mainly derived from long-term funds, that is, long-term funds are not only used for stable liquid assets and long-term assets, but also for temporary liquid assets. Third, the matching structure means that the source of funds is mainly determined by the use of funds, that is, the funds required for stable liquid assets and long-term assets are provided by long-term funds, and the funds required for temporary liquid assets are solved by current liabilities.

It can be seen that the matching structure among the three structures is the most ideal, which will not increase the pressure on the short-term debt repayment, but also ensure the efficiency of the enterprise. The quality of financing under this state is the appropriate. Therefore, enterprises should try to adjust the matching form of the source and use of funds to the matching structure to effectively improve the quality of corporate financing.

\section{IMPROVING THE QUALITY OF FINANCIAL RELATIONSHIPS (AN IMPORTANT WAY)}

The quality of financial relationship refers to the degree to which the financial relationship of the enterprise affects the efficiency of the creation of financial activities and the pros and cons of the results. It is an indispensable part of the financial quality of the enterprise. With the development of modern enterprise system, some experts and scholars have begun to re-examine financial relations from different perspectives, trying to construct new financial relationships, such as the construction of financial relationships based on the perspective of emerging factor capital, based on the perspective of corporate performance, based on the perspective of a harmonious society, and the construction of corporate financial relationships based on the perspective of social responsibility. However, based on the research purpose of this paper and the definition of the quality of financial relationship, the author mainly adjusts the internal financial relationship from fairness and efficiency to improve the efficiency of value creation, and pays attention to the external financial relationship credit management based on supply chain to optimize the value creation result. The idea of providing financial improvement for enterprises is not limited to this.

\section{A. Internal Financial Relationship}

Efficiency and fairness are fundamental issues in economics. The failure to solve the financial relationship fairness problem will affect the efficiency of financial activities, which leads to the inefficiency of the company's value creation. This problem is precisely the breakthrough point for improving the financial quality of the enterprise. The fair handling of agency relations and labor relations is particularly prominent.

1) Agency relationship: The use of incentives and fair handling of principal-agent relationships is the most effective way to improve the quality of agency relationships. The modern enterprise system in which the two powers are separated inevitably brings about agency problems. The key point for the enterprise to properly handle the financial relationship between the principal and the agent is to design the incentive and restraint system for the operator, to play the role of the compensation committee, to evaluate the performance of the operator fairly, to reward the lazy, and to 
link the income of the operator with the performance of the company, avoiding the problem of insufficient incentives and excessive incentives.

2) Labour relations: The relationship between labor and management is not a zero-sum game as the mainstream view puts. The compensation of employees can be treated fairly, and the enthusiasm and initiative of employees can be improved, which could help the healthy development of enterprises and reduce the consumption of raw materials and resources. It is entirely possible for both employers and employees to achieve a "win-win" situation. American scholar Lacker analyzed the rationality of the proportion of labor income in the value-added amount. After analyzing the relevant statistics of the United States for 50 years, he found that the wage and value of workers are two extremely positive variables. That is, wages should account for $39.395 \%$ of the total value added. If a company's wages are higher than this ratio, measures should be taken to increase labor productivity. Otherwise, the salary should be increased. At present, although neither the policy nor the academic circles have established quantitative criteria for employee compensation levels, according to Professor Gan's research, companies can use the Lacker coefficient to analyze whether the employee compensation level is reasonable, whether the labor-management relationship is harmonious, and whether the value creator's value distribution is fair to explore ways to improve the quality of financial relationships.

\section{B. External Financial Relationship}

The external financial relationship of the enterprise mainly includes the financial relationship between the enterprise and shareholders, creditors, tax authorities, debtors, suppliers, customers and the community. The quality of the relationship between enterprises and shareholders, creditors, and tax authorities is deeply dependent on the quality of financial activities, that is, the high efficiency of enterprise creation means that their fundamental interests are satisfied with achievability, as described above. The degree of pros and cons is the value distribution problem, and the research on the nature and coordination of the relationship with the above external stakeholders has also been discussed in a large number of literature studies. Therefore, this paper mainly provides ways to improve the quality of financial relations from the perspective of strengthening the credit management of supply chain entities such as debtors, suppliers and customers.

China's market economy has entered the buyer's market stage. Credit sales and credit loans have been an inevitable choice for enterprises to seize customer resources and increase market share. On the one hand, enterprises face fierce market competition and are in a risky credit environment. They must adopt appropriate credit policies and provide credit sales of a certain scale to enhance their competitiveness. On the other hand, the formulation and implementation of the credit policy provides the trusted enterprise with the opportunity to defer payment, but the result is that the high level of accounts receivable leads to the generation of bad debts and the difficulty of capital turnover, which makes the credit enterprises face huge Credit risk and loss.

Although there has exist external reasons such as macroeconomic environment, industry status, soundness of social credit system, and solvency of customers, there are also internal reasons such as the timeliness and integrity of information acquisition, credit management awareness, and establishment of credit management system. Enterprises must improve and innovate in terms of concepts, management techniques, and systems, and strengthen credit management in order to enhance the "recovery" of business activities and financial activities, and improve the financial quality of enterprises. According to the existing research in the academic field, the following recommendations are made:

First, it is essential to establish a corporate credit culture. Enterprises should strengthen the cultivation of credit management concepts on the basis of strengthening their own credit culture construction.

Second, it is significant to develop a credit policy that suits the company's own characteristics. The external factors that restrict the formulation of corporate credit policies include macroeconomic conditions, industry conditions, and credit policy tools. The internal factors that restrict corporate credit policy development include enterprise development strategy, management status, product life cycle, number and quality of target customers, etc. It is necessary to comprehensively consider these many influencing factors and choose a credit policy that suits their own situation and is conducive to maximizing the value of the enterprise.

Third, it is urgent to establish and improve the internal credit management system. The implementation of the corporate credit policy depends on the rational design of the internal credit management system. In terms of management means, it is indispensable to set up a credit management functional department; in terms of technical means, an efficient credit information technology support system should be built within the enterprise. On the basis of purchasing information hardware, it is necessary to establish a scientific credit management system, and develop a more comprehensive credit management system.

Finally, it is appropriate to establish a credit risk transfer mechanism, strengthen credit risk control and management, to ensure the company's funds are safe and complete, and avoid operational risks.

\section{CONCLUSION}

The improvement and realization of the quality of listed companies depends on the financial quality. Although the financial statements of the company are full of figures, the way to explore the improvement of financial quality must jump out of the complicated trivial digital maze, based on the company's specific business environment and business strategy. Companies should analyze the company's business scope and competitive advantages, and identify the opportunities and risks facing the company. Only in this way 
can enterprises truly return from the financial statements to the business activities of the company, improve the quality of financial information, asset quality, profit quality and financial relationship, and explain the business strategy and management quality of the company from the financial quality, thus fundamentally enhancing core competitiveness and ultimately improving corporate quality.

\section{REFERENCES}

[1] The Company's Financial Quality Being in Line With The Company's Quality [N]. China Business News,2014-06-09(B07).

[2] Ye Chenggang, Qiu Li, Zhang Lijuan. Corporate Governance Structure, Internal Control Quality and Corporate Financial Performance [J]. Auditing Research, 2016(02):104-112.

[3] Lu Xingfeng. Thoughts on the Construction of New Financial Information System Based on the Integration of Business and Finance - Taking New Retail as an Example [J]. Finance and Accounting Monthly), 2018(09):98-102.

[4] Dai Xiaoyu. Thoughts on the Improvement Path of Accounting Information Quality in Enterprise Financial Management [J]. China Township Enterprises Accounting, 2015(08):127-128.

[5] Li Xiaojing. The Research on Fiancial Quality Analysis of Enterprises [D]. Xia Men University, 2007.

[6] Li Xiaoli. The Study of Corporation Credit Policies' Lackness \& It's Improvement Manners [D]. Dalian Maritime University, 2011.

[7] Li Pingping, Yuan Jianhua. The Construction of New Enterprise Financial Relationship [J]. Commercial Accounting,2015(04):67-69..

[8] Suo Weiwei. Talking about Enterprise Financial Information Management [J]. Journal of Shanxi University of Finance and Economics),2012,34(S2):50.

[9] Guo Tingting. Listed Company's Financial Quality Evaluation Research in Our Country [D]. 2014. 